\title{
Imagined Contact Improves Intentions towards a Hypothetical Peer with Asperger Syndrome but not Attitudes towards Peers with Asperger Syndrome in General
}

\author{
Eleni Fleva ${ }^{1, *}$ \\ ${ }^{1}$ University of Reading, Reading, Berkshire, UK \\ *Correspondence: Research Associate-Language Development Lab, Department of Theoretical and Applied \\ Linguistics, School of English, Faculty of Philosophy, 541-24, Aristotle University, Thessaloniki, Greece. E-mail: \\ eleni.fleva@googlemail.com
}

Received: December 6, 2014

Accepted: December 12, 2014 Online Published: December 23, 2014

doi:10.5430/wje.v5n1p1

URL: http://dx.doi.org/10.5430/wje.v5n1p1

\begin{abstract}
The aim of this study is twofold. First, to investigate whether the imagined contact method (an indirect method of contact) can improve behavioural intentions towards a hypothetical peer with Asperger syndrome (AS). Second, to test whether the effect of the method can be generalised on attitudes towards young people with AS in general.Participants were 416 young adolescents $(M$ age $=15.2)$ who view a power-point presentation introducing a hypothetical male target with AS. A voice-over provided either descriptive or combined (descriptive plus explanatory) information about AS. Next, imagined contact participants were asked to imagine an encounter with the target boy while control participants were asked to simple think about him. Behavioural intentions towards the target were assessed by the Shared Activities Questionnaire while attitudes towards young people with AS in general were assessed by the Asperger Syndrome Questionnaire, a self-generated instrument. Results revealed that imagined contact compared to control participants exhibited greater behavioural intentions towards the target. However, no effect of the imagined contact method was observed on attitudes towards young people with AS in general. Combined information about AS had only a moderate effect. Implications and study limitations are discussed.
\end{abstract}

Keywords: imagined contact; Asperger syndrome; descriptive and combined information

\section{Introduction}

Children with Asperger syndrome (AS) and autism are at great risk of peer victimization. Little (2002) found that peer victimization is 4 times more likely to occur among children on the spectrum compared to their typically developing (TD) peers. Similarly, Carter (2009) found that $64.7 \%$ of children on the spectrum had been victimized and shunned by their peers during the past years. Attwood (2006) proposed that although all children with disabilities are at great risk of peer victimization this is particularly the case for children on the spectrum due to the nature of the condition. That is, they perfectly fit the profile of being potential targets of bullying as they appear to be shy, quiet-loners with a limited or no peer network (Attwood, 2006). Importantly, children on the spectrum significantly lag behind on their social skills (Smith-Myles \&Adreon, 2001), key ability for a successful peer interaction (Adreon\& Stella, 2001). Even when children on the spectrum are not targets of negative behavior they are usually socially excluded and are less nominated as "best friends" by their TD peers (Chamberlain, Kasari\&Rotheram-Fuller, 2007; Kasari, Locke, Gulsrud\&Rotheram-Fuller, 2011). For instance, Campbell et al (2004) found that TD children reported greater behavioural intentions towards a hypothetical TD target than towards a target presented with autism-related symptomatology. Similar findings were found on attitudes and behavioural intentions towards a hypothetical target presented as having Asperger syndrome (Fleva, 2014).

A number of interventions have been developed in order to facilitate interaction between typically developing students and students on the spectrum. Chan, Lang, Rispoli, O' Reily, Sigafoos and Cole (2009) reviewed forty-two studies which implemented peer-mediated interventions among children with Autism Spectrum Disorders (ASD) and 
found that $90 \%$ of the studies revealed positive outcomes of the intervention. However, Chan et al. acknowledged that an important limitation is that the studies above were not assessed for ecological validity and also for long-lasting effects. Thus, it is not known whether TD peers would continue befriending students on the spectrum outside of a highly supervised-research context. Importantly, in these kind of interventions the focus child is "predominantly the recipient" (Whitaker, Barratt, Helen, Potter \& Thomas, 1998, p. 64) and the interaction is more as a helper-helpee relationship rather than as a mutual friendship (Whitaker et al., 1998). Whitaker et al. (1998) found that only three of the forty TD children that were involved in a peer-mediated intervention referred to the child with autism as their friend. A further limitation of the peer-mediated interventions is that placing attention on the target child runs a risk of stigmatization (e.g., Chan et al., 2009; Whitaker et al., 1998) which in turn might triggers negative behaviours (Whitaker et al., 1998). The literature indicates that negative attitudes towards peers with disabilities is the result of ignorance about the condition but also the result of not having personal contact with individuals with the condition (e.g., Nevill\& White, 2011). The present study combines the provision of information about AS and the opportunity to experience an indirect contact with a person with AS with the ultimate goal to develop an intervention to ameliorate relations between TD adolescents and adolescents with AS.

\subsection{The Impact of an Educational Message on Attitudes and Intentions towards ASD}

In 2002 Nabors and Larson proposed that attitudes towards peers with disabilities can be improved by the provision of descriptive and explanatory information. Descriptive information highlights similarities between the audience and the child with the disability while explanatory information provides an explanation about the child's disability to the audience. Studies have used descriptive, explanatory or combined (descriptive plus explanatory) information to improve children's attitudes towards peers with various conditions, such as towards obese peers (Bell \& Morgan, 2000), peers with epilepsy and diabetes (Potter \& Roberts, 1984), Tourette's syndrome (Friedrich, Morgan \& Devine, 1996), visual impairment (Siperstein\&Bak, 1980), or towards wheelchair-bound peers (Nabors \& Larson, 2002). However, the results have provided inconsistent findings about which type of information triggers more positive responses towards peers with disabilities. These two information types have been tested on attitudes and intentions towards peers on the spectrum but again with inconsistent results. For instance, Swaim and Morgan (2001) found that explaining autism has no effect on attitudes and intentions towards a peer presented with the condition. Similar results were found by Fleva (2014) on attitudes and intentions towards a hypothetical peer presented as having Asperger syndrome. In contrast, Campbell, Ferguson, Herzinger, Jackson \& Marino (2004) found that an educational message about autism had a positive effect on attitudes for younger (age 9 and 10) but not for older (age 11) participants whereas there was a positive effect on behavioural intentions across all age groups. The finding that an educational message has no overall advantage on attitudes and intentions is somehow unexpected, as it was anticipated, that by explaining the causes of a condition and thus pointing out that the person is not responsible for his/her behaviour positive attitudes would be elicited. One of the aims of this study is to re-examine the effect of educational message on behavioural intentions and attitudes towards both a target presented as having AS but also towards young people with AS in general.

\subsection{Intergroup Contact}

In 1954 Gordon Allport proposed the contact hypothesis which states that contact can ameliorate intergroup relations by means of reducing prejudice and stereotypes that are often mediating intergroup relations (Allport, 1954). Indeed, a meta-analysis of more than 500 studies has shown a significant positive correlation between contact and stereotype reduction (Pettigrew \&Tropp, 2006). Crisp and Abrams (2008) proposed that contact can eliminate the boundaries between the social category " $u s$ " to a more inclusive category "we". The effect of contact on improving attitudes may be based on its ability to influence the three components of attitudes, affective, behavioural and cognitive (Hogg \& Vaughan, 2002). Contact is hypothesized to improve the cognitive representation of the outgroup (the cognitive component) by enriching knowledge about the outgroup (Turner, Crisp \& Lambert, 2007). Greater knowledge in turn, reduces the outgroup homogeneity effect (Quattrone\& Jones, 1980), i.e., the stereotypes that outgroup members lack variability in terms of characteristics, behaviour and beliefs compared to ingroup members (Turner et al., 2007). In other words, knowledge reduces group-based stereotypes. Greater knowledge in turn, lessens anxiety (the affective component) that is often present on the first encounter with outgroup members (Turner et al., 2007). More knowledge and less anxiety can predict greater self-confidence during an encounter with outgroup members similar to notions of perceived behavioural control. This increases the probability that an interaction will be initiated when the opportunity is presented (the behavioural component) (Turner et al., 2007). Therefore, contact has the ability to change the three components that make up an attitude and thus to result in positive behaviours towards the attitude 
object.

Direct contact, however, might not always be feasible due to a lack of opportunities to interact with the outgroup. Consider cases in which physical segregation intervene meaningful interaction between different social groups. For instance, Catholics and Protestants in Northern Ireland have limited contact opportunities as only 5\% of children attend a mixed Catholic-Protestant school (Turner, Hewstone\&Voci, 2007). Another example is coming from the United States between Latino and White communities (Martin, 2006) but also from Cyprus in relation to the Green Line and from the West Back in Israel (Crisp \& Turner, 2009). The solution in such cases is offered by the extended contact (Wright, Aron, McLaughlin-Volpe \&Ropp, 1997), i.e., the knowledge that a group member is maintaining a close relationship with an outgroup member (Turner et al., 2007). Extended contact has successfully benefit intergroup relations (Paolini, Hewstone, Cairns \&Voci, 2004) by "changing perceptions of ingroup norms" (Turner, Hewstone, Voci\&Vonofakou, 2008 cited in Dovidio, Eller \&Hewstone, 2011, p. 152). Extended contact has also revealed positive outcomes in improving attitudes of TD children towards peers with disabilities. Cameron and Rutland (2006) showed that 5-10 year old children who read stories portraying TD children befriending children with disabilities showed more positive attitudes and behavioural intentions towards those peers compared to control participants. In other words, extended contact may improve attitudes by knowing that "my friend's friend is my friend" (Dovidio et al., 2011, p. 150).

However, there are cases where even extended contact is not feasible. For example, in highly segregated social groups there may be no ingroup members who interact with outgroup members. In these cases the answer seems to be the relatively-newly developed imagined contact hypothesis (Crisp \& Turner, 2009). Participants in a typical imagined contact study are instructed to imagine that the interaction with the outgroup member is pleasurable and that during the interaction they (usually) discover some positive and interesting things about the outgroup member (Stathi\& Crisp, 2008). Imagined contact is based on the mental imagery notion that is seeing with the "mind's eye" (Galton, 1883, p. 312) and is defined as "the mental simulation of a social interaction with a member or members of an outgroup category" (Crisp \& Turner, 2009, p. 234). Mental imagery has been applied in many areas in psychology such as, clinical (Wolpe, 1958), cognitive (Paivio, 1968), and personality (Markus \&Nurius, 1986) psychology. A growing body of research has shown that imagined contact improves intergroup attitudes (Turner, Crisp \& Lambert, 2007) even among socially segregated groups (Husnu\& Crisp, 2010), increases perception of positive traits to the outgroup (Stathi\& Crisp, 2008) and facilitates future contact intentions (Husnu\& Crisp, 2010) while at the same time it reduces the outgroup homogeneity effect (Turner et al., 2007). The method has revealed positive effects even among young children on attitudes towards children from other ethnic-outgroups (Stathi, Cameron, Hartley \& Bradford, 2014) and towards peers with disabilities (e.g., Cameron, Rutland, Turner, Holman-Nicolas \& Powell, 2011) rendering the method as a promising prejudice reduction-intervention for use in school settings (Stathi et al., 2014). The effectiveness of mental imagery appears to stem from its similarity to real experiences. That is, it activates the same emotional and motivational responses (Dadds, Bovbjerg, Redd\&Cutmore, 1997) and the same neurological mechanisms (i.e., memory and motor control) (Kosslyn, Ganis\& Thompson, 2001) as in real situations. Additionally, mental imagery can involve the same concrete details and causal sequences as real experiences (Dadds et al., 1997) and can have a powerful effect on learning and decision making (Taylor, Pham, Rivkin\& Armor, 1998).

Imagined contact is an even more indirect method than extended contact and thus its effect may not be as strong as direct or extended contact (Crisp et al., 2009). However, in contrast to extended contact, imagined contact does involve an interaction that takes place between the self and the outgroup member (Dovidio et al., 2011). Following this premise imagined contact can be considered to resemble better actual contact than extended contact (Dovidio et al., 2011). Although imagined contact might be less effective than actual contact it has significant advantages over actual contact. For example, similarly to the extended contact it prepares the person for a future encounter by controlling for possible anxiety that might occur in first-time face-to-face interactions, that is, imagined contact can function as an anxiety buffer mechanism in the same way that systematic desensitization functions in, say, treatment of a phobia (Crisp et al., 2009). In other words, imagined contact aims to make people mentally "relaxed" for a future encounter with the outgroup (Crisp et al., 2009). If people have previously mentally experienced a situation (i.e., an interaction with the outgroup) they will feel more confident to encounter this interaction in real settings as in some way they have already experienced it. Also, if this mental interaction is a pleasurable interaction then the person might approach the outgroup with positive intentions and expectations. Approaching an outgroup member with positive intentions is likely to result in a positive actual contact, which will contribute to the already existent positive 
effect of imagined contact, which in turn is highly likely to positively affect attitudes towards that person (Dovidio et al., 2011).

\subsection{Purpose of the Study}

The primary aim of this goal is to test the efficacy of the imagined contact method as an intervention to improve young adolescent's behavioural intentions towards a hypothetical peer presented as having AS and whether the potential positive effect of the method can be generalized towards young people with AS in general. This study also assess the impact of a brief educational message about AS. To achieve the above goals participants view a power-point presentation of a hypothetical target with AS while a voice-over provided either descriptive information (highlighting similarities between participants and the target) or combined information (highlighting similarities between participants and the target but also briefly explaining what AS is). Next, participants were randomly allocated to either an imagined contact condition in which they envisage an interaction with the target or to a control condition in which they envisage the presence of the target but no interaction occurred. Participants intentions to engage in social, academic and recreational activities with the target are assessed as well as attitudes towards young people with AS in general.This study aims to address the following research questions:

a) Are behavioural intentions towards the hypothetical target with AS improved when participants engage in an imagined contact compared to when they just think about the presence of the target with AS?

b) Are attitudes towards young people with AS in general improved when participants engage in an imagined contact compared to when they just think about the presence of the target with AS?

c) Is descriptive or combined information more effective in improving participants' intentions towards the target and attitudes towards people with AS in general?

d) Do participants exhibit any preference for performing social, academic or recreational activities with the target?

\section{Method}

\subsection{Research Design}

The study had a between-subjects design with two principal independent variables: imagined task (imagined contact vs. no imagined contact[control]) and information type: (descriptive vs. combined information). An additional independent variable was participants' gender (boys vs. girls). The two dependent variables were participants' willingness to perform social, academic and recreational activities with the hypothetical target with AS as measured by the SAQ as well as their attitudes towards young people with AS in general, as measured by the Asperger Syndrome Questionnaire (ASQ), a self-generated measurement. Participants were tested in classroom settings and classes were randomly allocated to one of the following four conditions in a $2 \times 2$ between-subjects design:

1) Participants engaged in an imagined contact with a hypothetical boy with AS and received descriptive information

2) Participants imagined the presence (no contact) of the hypothetical boy with AS and received descriptive information

3) Participants engaged in an imagined contact with a hypothetical boy with AS and received combined information

4) Participants imagined the presence (no contact) of the hypothetical boy with AS and received combined information

\subsection{Participants}

Participants were recruited from a mixed lower secondary and a mixed higher secondary school in Athens, Greece. Participants' age varied between 12 and 18 years $(M$ age $=15.2)$. The schools were the data collected from are medium size mainstream schools. Consistent with the town's population, the school has a very small proportion of pupils from different ethnic minorities. The Head Teacher of both schools indicated that teachers have not received any special training about students with ASD or other disabilities. In order to assess the effect of imagined contact on TD students towards their peers with AS but also due to ethical reasons, only classes that did not include students with ASD were asked to participate. 
Children were recruited through a parental consent form sent home from school along with information about the study. Information for children was also sent home from school. In order to participate, students were asked to give written consent before the study began. Only students who signed consent forms and whose parents had signed consent forms participated in the study. Participants were tested as a group in classroom settings. Before the study was conducted, ethical approval was granted by the University of Reading Ethics Committee and permission was given by the Head Teacher of the school to carry out the data collection.

\subsection{Measures}

All participants were administered with the Shared Activities Questionnaire (SAQ) (Morgan, Walker, Bieberich\& Bell, 1996) and the Asperger Syndrome Questionnaire (ASQ), a self-generated instrument.

Shared Activities Questionnaire (SAQ).The SAQ consists of 24 items that assess attitudes and behavioural intentions of TD children towards disabled peers. The items are split into three categories of interest: General Social (companionship with the target child at school) Academic (willingness to engage in academic activities with the target child) and Active Recreational (outside school activities with the target child). The SAQ was translated into Greek for the purpose of this study.

Asperger Syndrome Questionnaire (ASQ).This is a self-generated questionnaire designer to measure participants' feelings towards young people with AS in general. This questionnaire was developed by the author and reviewed by NHS clinical psychologist expert in the area of ASD and was reviewed by NHS members working with children and young adolescents with ASD. The scale consisted of 8 questions in total. At the beginning of the questionnaire participants were informed that the following questions should be answered based on how they feel about young people with AS in general and not just towards the particular imagined target. Next, Participants were first asked to indicate on a 5-point semantic differential scale how "friendly-unfriendly", how "warm-cold" (derived from Voci\&Hewstone, 2003), how "worried-confident" and how "happy-unhappy" they felt towards young people with AS in general. This was followed by some questions from the Chedoke-McMaster Attitudes Towards Children with Handicaps (CATCH) scale (Rosenbaum et al., 1986). The following three items were selected and modified to probe feelings towards AS: "I feel sorry for children with $A S$ ", "I would be afraid of a child with AS", "Children with $A S$ are as happy as I am". Participants were asked to respond on a 5-point Likert scale ranging from 1= strongly agree to $5=$ strongly disagree. Using the same 5-point Likert scale, participants were aslo asked to report the degree of their agreement with the following statement "Children with AS are just the same as other children in my class". These questions aimed to identify outgroup anxiety and ingroup preference.

Vignettes and Power-point Presentation.Two sets of vignettes were developed one with descriptive information and one with combined information. Descriptive information highlighted similarities between the target and the participants (e.g., "John is about the same age as you") but also highlighted behavioural aspects and characteristics that are common among children and young adolescents with AS. For instance, participants were informed that the target child "spends most of his lunchtime and breaks on his own" or that the target child "does not always understand jokes". Regarding the target's interests, he was described to have similar interests as the TD target but to be more preoccupied. For example, similarly to the TD target participants were told that the target with AS likes football but that he likes it so much that he "can remember the results of every single match played by his favourite team".

Combined information, on the other hand, provided the same information as above but with an additional brief educational message about AS. Thus, participants were told that the target child "has Asperger's syndrome, which means that he has difficulties talking to other people and understanding what they feel or think. Asperger syndrome is something that you are born with and it affects the way the brain works. People with Asperger syndrome can learn to do many of the things that other people can do, they just need more time and help". Additionally, participants provided with combined information about the target with AS were informed that some of the target's behaviour was due to his condition. For instance, they were informed that "like many people with Asperger syndrome [the target's child] wants to make more friends, but doesn't know how to". Particular care was waken for the two vignettes to be of the same length. The vignettes were read out by a young male who pretended to be the target's friend. During the reading vignette process the voice was recorded. The vignettes were piloted with ASD-experienced practitioners in the NHS to ensure the accuracy of the passage attempting to describe an adolescent with AS. 
To develop the Powerpoint presentation a series of pictures were taken of a young boy (of the same age as the participants) performing daily activities in his home (e.g., playing, studying, eating). The recorded voice matched the pictures of the target and participants viewed the target on a Powerpoint presentation.

\subsection{Procedure}

Participants were tested in classroom settings and whole classes were allocated to conditions. A teacher was present during each experimental session. Initially participants viewed the power-point presentation and at the end the voice-over instructed participants to close their eyes and to either imagine interacting with the target or to just imagine his presence in the class (control participants). Participants in the imagined contact condition listen the voice-over to instructed them to imagine that "John sits next to you...the teacher asks the classroom to do a group exercise...your group finishes the exercise... and you asked John if he has watched the new movie and what he likes to do...while he is talking you find out some interesting, positive and unexpected things about him". Control participants, on the other hand were instructed to imagine that the target child sits further away from them and thus there was no imagined interaction with him. Thus, participants in both imagined scenarios envisaged the presence of the target but only one group engaged in an imagined contact.

Next, the voice-over asked participants to open their eyes and they were administered with the SAQ and the ASQ.

\subsection{Data Analysis Procedure}

To assess behavioural intentions towards the target as measured by the SAQ participants received three points for every "yes" response, two points for every "maybe" response and a one point for every "no" response. Thus, the maximum score a participant can get is 72 (a "Yes" response to all items) and the minimum score is 24 (a "No" response to all items).

Regarding the ASQ and prior to any analysis a Principal Component Analysis (PCA) with varimax rotation was performed in order to identify which items load on the same factor. Inspection of the data found three components with an eigenvalue of greater than 1.0 which also confirmed by the scree plot. The components can be considered as representing the following areas of attitudes towards young people with AS: positive feelings towards young people with AS, anxiety or avoidance of young people with AS and similarity of self or others to young people with AS. Based on this, the first component was named "positive regard", the second component "anxiety/avoidance" while the third component was named "similarity". The analysis was performed based on these three components. The scores of the two questionnaires were transferred to the statistical package for social sciences (SPSS) version 20. A 2 (imagined activity: imagined contact vs. no imagined contact) by 2 (information type: descriptive vs. combined) by 2 (gender: boys vs. girls) ANOVA was performed separately for each of the three components of the SAQ (social, academic, recreational) and separately for each of the three ASQ component scores (positive regard, anxiety avoidance, similarity). In any post-hoc analyses following the ANOVAs, all p-values have been subjected to appropriate Bonferroni corrections for four comparisons. Thus, the new critical alpha level set in the present study is $\alpha_{\text {crit }}=.0125$. 


\section{Results}

The means and standard deviations obtained by the analyses of the SAQ and the ASQ are displayed in Table 1 below

Table 1. Mean Scores of the SAQ and ASQ (standard deviations in parentheses) as a Function of Participant Gender, Information Type and Imagined Activity Condition

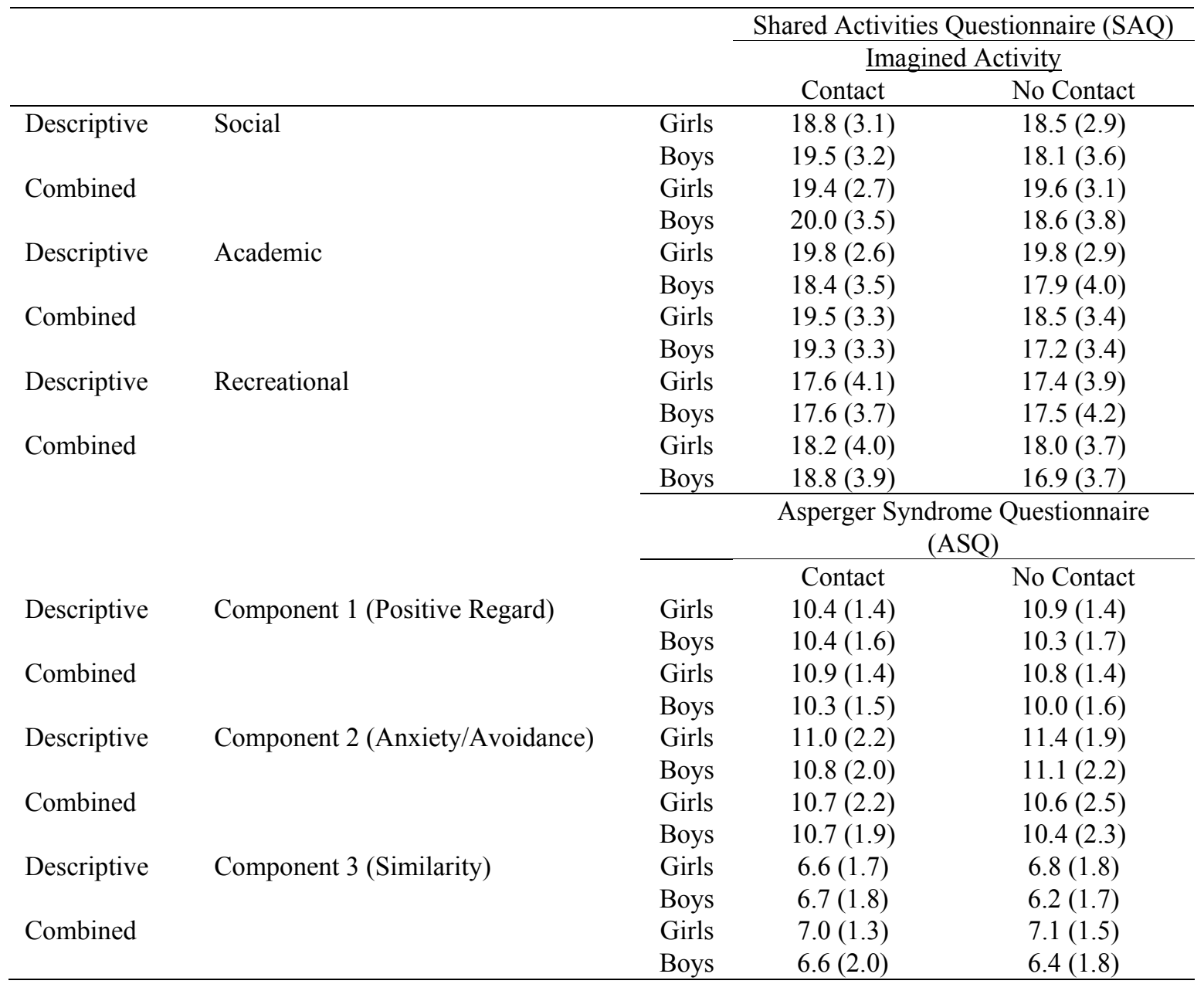

\subsection{Behavioural Intentions towards the Target with AS (SAQ)}

The analysis of the SAQ social scores revealed a significant main effect of imagined activity with participants in the imagined contact condition reporting greater intentions than control participants $[M=19.3$ vs. $M=18.7, F(1,400)=$ $\left.3.76, p=.05, \eta^{2}=.009\right]$. A significant main effect of information type was also found with combined information resulting in higher scores than descriptive information $\left[M=19.4\right.$ vs. $\left.M=18.5, F(1,400)=7.84, p=.005, \eta^{2}=.01\right]$.

The analysis of the SAQ academic scores revealed a significant main effect of imagined activity with participants in the imagined contact condition reporting greater intentions than control participants $[M=19.3 \mathrm{vs.} M=18.3, F(1,400)$ $\left.=7.34, p=.007, \eta^{2}=.01\right]$. A main effect of gender was also found with girls scoring higher than boys $[M=19.4$ vs. $\left.M=18.2, F(1,400)=11.1, p=.001, \eta^{2}=.02\right]$. A significant interaction between imagined activity and information type was also found, $F(1,400)=4.09, p=.04, \eta^{2}=.01$. To analyse the interaction independent sample t-tests were performed examining the effect if imagined activity on descriptive and combined information separately. Combined information was more effective in the imagined contact than in the control condition $[M=19.4$ vs. $M=17.8, t(219)=$ $\left.-3.55, p<.001<p_{\text {crit }}=.012\right]$. Scores for the descriptive information did not differ significantly between the two conditions $\left(p=.45>p_{\text {crit }}=.012\right)$.

For the SAQ recreational activities the main effect of imagined activity was found not to be statistically significant $(p=.12)$ nor were there any other significant main effects or interactions.

A 3 (Activity type: social, academic, recreational) by 2 (gender: boys vs. girls) repeated measures ANOVA was performed to see whether participants exhibit any preference to engage in certain kind of activities with the target. A 
Greenhouse-Geisser adjusted correction was used $(\varepsilon=.87)$ as the Mauchly's test indicated that the assumption of sphericity had been violated, $\chi^{2}(2)=68.2, p<.001$. Means indicated that participants preferred to engage in social $(M=19.1, S . D=3.3)$ followed by academic $(M=18.8, S . D=3.4)$ and then by recreational $(M=17.8, S . D=3.9)$ activities with the target. Significant differences were found between the three types of activities, $F(1.74,749.7)=$ 43.18, $p<.001, \eta^{2}=.09$. Bonferroni post-hoc tests suggested significant differences between academic and recreational $(M=18.8$ vs. $M=17.8, p<.001)$ and between social and recreational $(M=19.1$ vs. $M=17.8, p=.001)$ activities. Thus, participants showed significantly stronger intentions to perform social and academic rather than recreational activities with the target.

\subsection{Attitudes towards Young People with AS in General (ASQ)}

The main effect of imagined activity was found not to be statistically significant for neither component 1 (Positive Regard) $(p=.12)$, nor for component 2 (Anxiety/Avoidance) $(p=.90)$ or for component 3 (Similarity) ( $p=.78)$. A significant main effect of gender was found for component 1 with girls scoring significantly higher than boys $[M=$ 10.8 vs. $\left.M=10.2, F(1,400)=12.6, p<.001, \eta^{2}=.03\right]$. Similarly, girls scored greater than boys for component $3[M=$ 6.9 vs. $\left.M=6.4, F(1,400)=5.8, p=.016, \eta^{2}=.01\right]$ but not for component 2 . No significant main effect of information type was found throughout the analysis of the ASQ.

\section{Discussion}

\subsection{Findings Regarding the Imagined Contact Method}

This study successfully showed that imagined contact can ameliorate young adolescents' behavioural intentions towards a hypothetical peer presented as having AS. However, this effect found not to be generalized towards other young people with AS in general. This was an unexpected finding and does not accord with the literature showing that the effect of the imagined contact can be generalized from an outgroup member towards the whole outgroup (Stathi et al., 2011). The lack of such an effect might have been due to some methodological limitations. For instance, the ASQ is a self-developed measurement and thus it may have been a not sufficiently sensitive instrument to detect differences in attitudes, although a factor analysis suggested that three components contributed to the overall score, with strong inter-correlations of items loading on each factor. Another reason accounted for the lack of an effect on attitudes could have been that the ASQ was administered second following by the SAQ and the effects may have not been strong enough to generalize towards people with AS in general. In other words, order effects may have a negative impact on attitudes. Finally, different levels of information that was presented about the target and about people with AS in general might have resulted in an effect on intentions but no on attitudes. That is, participants had a more rich cognitive representation of the target compared to people with AS in general. Participants saw a picture of the target during the presentation and thus they already had a mental picture of him before they were asked to imagine an interaction with him (or his presence) in the imagined contact condition. In contrast, attitudes towards people with AS in general were assessed following brief information and without any pictures of young people with AS. Visual aids increase vividness, which, enhances the imagined contact effectiveness and thus improve attitudes (Cameron et al., 2011).

In relation to the effect of the imagined contact method upon behavioural intentions an effect was found for social and academic but not recreational activities. This may occurred due to the match between the content of the imagined contact scenario and the environment in which the study took place. That is, the study was conducted in a school environment and participants were asked to imagine meeting the hypothetical child at their school and perform a task related to an academic activity. Thus, participants' familiarity with the environment (school) but also familiarity with performing school-related activities with their peers may have enhanced the vividness of the imagined contact method for social and academic as opposed to recreational activities. Vividness has been found to positively affect the efficacy of the imagined contact method (Crisp et al., 2008). Familiarity may also have enhanced the children's ability to elaborate the scenario. Elaboration is a factor that has been found to positively affect imagined contact efficacy (Husnu\& Crisp, 2010). In other words, participants might find it easier to imagine engaging in an interaction with an unknown child in a familiar rather than in an unfamiliar environment.

\subsection{Findings Regarding Information Type and Participants' Gender}

There was not an overall advantage of educating participants about AS. In particular, combined compared to descriptive information had no effect on attitudes towards people with AS in general and only a small effect on social (but not academic or recreational) behavioural intentions towards the target with AS. It can be considered that overall the present findings of educating participants about ASD are in line with Fleva (2014) and Swaim and Morgan (2001) 
but in contrast to Campbell et al. (2004). However, it is important to keep in mind that this is the first study that examines the effect of the information provision in an imagined contact scenario. Further studies are needed before concluding that there is no advantage of combined compared to descriptive information in an imagined contact study.

A significant main effect of participants' gender showed that girls were more willing to engage in academic activities with the target compared to boys. This finding is in line with the literature (Campbell et al., 2004). Girls have been found to perform better than boys in academic activities and thus have greater intentions in this area than boys (e.g., Van Houtte, 2004). This might explain this gender difference in academic intentions. However, the finding that no gender differences emerged for social and academic activities could be due to the target being male. Girls might have felt that they have no common interests that would make them engage in social or recreational activities with a child of the opposite gender. Academic activities, on the other hand, are not uncommon to be performed by boys and girls in pairs. Thus, it is not known if girls would have exhibited more positive social and recreational (as well as academic) intentions if the target had been a girl and thus more likely to be perceived as a potential friend and having more in common with. This explanation becomes even more likely given that girls were overall more positive than boys in their attitudes towards people with AS in general as measured by the ASQ in which the items were not gender-specific.

\subsection{Findings Regarding Participants' Preference for Activity Type}

Participants exhibited higher intentions to engage in academic (and social) rather than recreational activities with the target. This preference could be explained by studies showing that even when children have positive attitudes towards peers with disabilities this is more at a superficial level, with fewer intentions for a deeper interaction (e.g., Gannon \&McGilloway, 2009). The same was also reported by Nikolaraizi and De Reybekiel (2001) who, similarly to this study, examined attitudes of children from Greece (and the UK) towards peers with disabilities. However, an alternative explanation for the greater academic but not social or recreational intentions is that the imagined activity scenario instructed participants to imagine the encounter taking place in a school environment and to perform academic-related activities. This, in turn, might have rendered the thought of performing this kind of activities more cognitively accessible compared to social and recreational activities. In other words, the content of the imagined activity scenario might have operated as a priming effect. Future studies could examine if participants show different preferences when they are engaged in an imagined contact scenario taking place in different environmental contexts.

\subsection{Study Limitations and Conclusion}

The findings of the present research needs to be approached in line with some limitations. As discussed before, order effects might have accounted for the lack of an effect on attitudes compared to intentions. This is something that can be examined in future studies by changing the order of instrument administration. A further limitation of this study is related to the target's gender. The SAQ required participants to indicate their willingness to perform various activities with the target. However, children and young people typically prefer to befriend same-rather than opposite-gender peers. Thus, in this study boy participants considered their intentions towards a same-gender target while girls considered their intentions towards an opposite-gender target. This might also explain the finding that girls were found to be more positive than boys only for academic, but not for social or recreational activities, while the literature indicates a robust general effect, with girls being more positive than boys towards peers with disabilities (e.g.,Panek\& Smith, 2005). Future studies should consider that the target's gender can have an impact on participants' responses and include both a male and a female gender. A possible criticism of this study could be the large sample size which might have resulted in significant effect of the imagined contact method but with small magnitude. Although this is not a likely explanation as the literature indicates positive effects of the imagined contact method even with small sample sizes.

Overall, this study can be considered to have successfully managed to improve participants' social and academic intentions towards a hypothetical unknown child with AS. The present research is believed to have significantly contributed to the imagined contact literature as it tested the method's efficacy among participants with limited familiarity with the outgroup, i.e., people in Greece. Most of the studies in the imagined contact literature have tested the method towards outgroups that participants are likely to have some degree of familiarity with (e.g., elderly people, homosexuals, Muslims, obese people). The work here, however, showed that imagined contact can be an effective method to ameliorate intentions even when, or maybe particularly, when it is applied with participants with restricted knowledge and familiarity with the outgroup. Additionally, the design of this research contributes to the literature as the scenario for the control participants was very close to the one for participants in the imagined contact scenario. The only difference was that imagined contact participants engaged in an imagined interaction with the outgroup (i.e., the targets with AS) while control participants did not. Finding an effect of the method when the two 
conditions are so similar to each other is a particular contribution of this work as it supports the use of imagining an outgroup interaction for improving intentions. Despite all, this study is believed to have promoted ASD awareness in a large sample size and to have paved the path for introducing the imagined contact method as a potential and easy to apply intervention in school settings.

\section{References}

Adreon, D., \& Stella, J. (2001). Transition to middle and high school. Intervention in School and Clinic, 36(5), 266-271. http://dx.doi.org/10.1177/105345120103600502

Allport, G. W. (1954). The nature of prejudice. Cambridge, MA: Addison-Wesley.

Attwood, T. (2006). The Complete Guide to Asperger's Syndrome. London: Jessica Kingsley Publishers.

Bell, S. K., \& Morgan, S. B. (2000). Children's attitudes and behavioral intentions toward a peer presented as obese: Does a medical explanation for the obesity make a difference? Journal of Pediatric Psychology, 25(3), 137-145. http://dx.doi.org/10.1093/jpepsy/25.3.137

Cameron, L., \& Rutland, A. (2006). Extended contact through story reading in school: Reducing children's prejudice toward the disabled. Journal of Social Issues, 469-488.http://dx.doi.org/10.1111/j.1540-4560.2006.00469.x

Cameron, L., Rutland, A., Turner, R., Holman-Nicolas, R., \& Powell, C. (2011). Changing attitudes with a little imagination: Imagined coontact effects on young children's intergroup bias. Anale de Psychologia, 27(3), 708-717.

Campbell, J. M., Ferguson, J. E., Herzinger, C. V., Jackson, J. N., \& Marino, C. A. (2004). Combined descriptive and explanatory information improves peers' perceptions of autism. Research in Developmental Disabilities, 25(4), 321-339. http://dx.doi.org/10.1016/j.ridd.2004.01.005

Carter, S. (2009). Bullying of students with Asperger syndrome. Issues in Comprehensive Pediatric Nursing, 32(3), 145-154.

Chamberlain, B., Kasari, C., \& Rotheram-Fuller, E. (2007). Involvement or Isolation? The social networks of children with autism in regular classrooms. Journal of Autism and Developmental Disorders, 37(2), 230-242. $\mathrm{http}: / / \mathrm{dx}$.doi.org/10.1007/s10803-006-0164-4

Chan, J. M., Lang, R., Rispoli, M., O' Reilly, M., Sigafoos, J., \& Cole, H. (2009). Use of peer-mediated interventions in the treatment of autism spectrum disorders: A systematic review. Research in Autism Spectrum Disorders, 876-889.

Crisp, R. J., \& Abrams, D. (2008). Improving intergroup attitudes and reducing stereotype threat: An integrated contact model. European Review of Social Psychology, 19(1), 242-284.

Crisp, R. J., \& Turner, R. N. (2009). Can imagined interactions produce positive perceptions?: Reducing prejudice through simulated social contact. American Psychologist, 64(4), 231-240. http://dx.doi.org/10.1037/a0014718

Dadds, M. R., Bovbjerg, D. H., Redd, W. H., \& Cutmore, T. R. (1997). Imagery in human classical conditioning. Psychological Bulletin, 122(1), 89-103. http://dx.doi.org/10.1037/0033-2909.122.1.89

Dovidio, J. F., Eller, A., \& Hewstone, M. (2011). Improving intergroup relations through direct, extended and other forms of indirect contact. Group Processes \& Intergroup Relations, 14(2), 147-160. http://dx.doi.org/10.1177/1368430210390555

Fleva, E. (2014). Attitudes and behavioural intentions of typically developing adolescents towards a hypothetical peer with Asperger syndrome. World Journal of Education, 4(6), 54-65. http://dx.doi.org/10.5430/wje.v4n6p54

Friedrich, S., Morgan, S. B., \& Devine, C. (1996). Children's attitudes and behavioral intentions toward a peer with Tourette syndrome. Journal of Pediatric Psychology, 21(3), 307-319. http://dx.doi.org/10.1093/jpepsy/21.3.307

Galton, F. (1883). Inquiries into human faculty and its development. London: Macmillan.

Gannon, S., \& McGilloway, S. (2009). Children's attitudes towards their peers with Down Syndrome in schools in rural Ireland: An exploratory study. European Journal of Special Needs Education, 24(4), 455-463. http://dx.doi.org/10.1080/08856250903223104

Hogg, M. A., \& Vaughan, G. M. (2002). Social Psychology (3 ${ }^{\text {rd }}$ ed.). London: Prentice Hall. 
Husnu, S., \& Crisp, R. J. (2010). Elaboration enhances the imagined contact effect. Journal of Experimental Social Psychology, 46(6), 943-950. http://dx.doi.org/10.1016/j.jesp.2010.05.014

Kasari, C., Locke, J., Gulsrud, A., \& Rotheram-Fuller, E. (2011). Social networks and friendships at school: comparing children with and without ASD. Journal of Autism and Developmental Disorders, 41(5), 533-544. http://dx.doi.org/10.1007/s10803-010-1076-x

Kosslyn, S. M., Ganis, G., \& Thompson, W. L. (2001). Neural foundations of imagery. Nature Reviews Neuroscience, 2(9), 635-642. http://dx.doi.org/10.1038/35090055

Little, L. (2002). Middle-class mothers' perceptions of peer and sibling victimization among children with Asperger's syndrome and nonverbal learning disorders. Issues in Comprehensive Pediatric Nursing, 25(1), 43-57. http://dx.doi.org/10.1080/014608602753504847

Markus, H., \& Nurius, P. (1986). Possible selves. Americal Psychologoist, 41(9), 954-969. http://dx.doi.org/10.1037/0003-066X.41.9.954

Martin, M. E. (2006). Residential segregation patterns of Latinos in the United States, 1990-2000. New York, NY: Routledge.

Morgan, S. B., Walker, M., Bieberich, A., \& Bell, S. (1996). The shared activities questionnaire. Unpublished manuscript, University of Memphis, Memphis, TN.

Nabors, L. A., \& Larson, E. R. (2002). The effects of brief interventions on children's playmate preferences for a child sitting in a wheelchair. Journal of Developmental and Physical Disabilities, 14(4), 403-413. http://dx.doi.org/10.1023/A:1020339004125

Nevill, R., \& White, S. (2011). College students' openness toward autism spectrum disorders: Improving peer acceptance. Journal of Autism and Developmental Disorders, 41(12), 1619-1628. http://dx.doi.org/10.1007/s10803-011-1189-x

Nikolaraizi, M., \& De Reybekiel, N. (2001). A comparative study of children's attitudes towards deaf children, children in wheelchairs and blind children in Greece and in the UK. European Journal of Special Needs Education, 16(2), 167-182. http://dx.doi.org/10.1080/08856250110041090

Paivio, A. (1968). A factor-analytic study of word attributes and verbal learning. Journal of Verbal Learning and Verbal Behavior, 7(1), 41-49. http://dx.doi.org/10.1016/S0022-5371(68)80161-6

Panek, P. E., \& Smith, J. L. (2005). Assessment of terms to describe mental retardation. Research in Developmental Disabilities, 26(6), 565-576. http://dx.doi.org/10.1016/j.ridd.2004.11.009

Paolini, S., Hewstone, M., Cairns, E., \& Voci, A. (2004). Effects of direct and indirect cross-group friendships on judgments of Catholics and Protestants in Northern Ireland: The mediating role of an anxiety-reduction mechanism. Personality and Social Psychology Bulletin, 30(6), 770-786. http://dx.doi.org/10.1177/0146167203262848

Pettigrew, T. F., \& Tropp, L. R. (2006). A meta-analytic test of intergroup contact theory. Journal of Personality and Social Psychology, 90(5), 751-783. http://dx.doi.org/10.1037/0022-3514.90.5.751

Potter, P. C., \& Roberts, M. C. (1984). Children's perceptions of chronic illness: The roles of disease symptoms, cognitive development, and information. Journal of Pediatric Psychology, 9(1), 13-27. http://dx.doi.org/10.1093/jpepsy/9.1.13

Quattrone, G. A., \& Jones, E. F. (1980). The perception of variability within in-groups and out-groups: Implications for the law of small numbers. Journal of Personality and Social Psychology, 38(1), 141-152. http://dx.doi.org/10.1037/0022-3514.38.1.141

Rosenbaum, P. L., Armstrong, R. W., \& King, S. M. (1986). Children's attitudes toward disabled peers: A self-report measure. Journal of Pediatric Psychology, 11(4), 517-530. http://dx.doi.org/10.1093/jpepsy/11.4.517

Siperstein, G. N., \& Bak, J. J. (1980). Improving children's attitudes towards blind peers. Journal of Visual Impairment and Blindness, 74(4), 132-135.

Smith-Myles, B., \& Adreon, D. (2001). Asperger Syndrome and Adolescence: Practical Solutions for School Success. Kansas/USA: Autism and Asperger Publishing Company.

Stathi, S., Cameron, L., Hartley, B., \& Bradford, S. (2014). Imagined contact as a prejudice-reduction intervention in schools: the underlying role of similarity and attitudes. Journal of Applied Social Psychology, 44(8), 
536-546.http://dx.doi.org/10.1111/jasp.12245

Stathi, S., \& Crisp, R. J. (2008). Imagining intergroup contact promotes projection to outgroups. Journal of Experimental Social Psychology, 44(4), 943-957.http://dx.doi.org/10.1016/j.jesp.2008.02.003

Stathi, S., \& Crisp, R., \& Hogg, M. A. (2011). Imagining intergroup contact enables member-to-group generalization. Group Dynamics: Theory, Research and Practice, 15(3), 275-284. http://dx.doi.org/10.1037/a0023752

Swaim, K. F., \& Morgan, S. B. (2001). Children's attitudes and behavioural intentions toward a peer with autistic behaviours: Does a brief educational intervention have an effect? Journal of Autism and Developmental Disorders, 31(2), 195-205. http://dx.doi.org/10.1023/A:1010703316365

Taylor, S. E., Pham, L. B., Rivkin, I. D., \& Armor, D. A. (1998). Harnessing the imagination.Mental simulation, self-regulation and coping. American Psychologist, 53(4), 429-439.

Turner, R. N., Crisp, R. J., \& Lambert, E. (2007). Imagining intergroup contact can improve intergroup attitudes. Group Processes \& Intergroup Relations, 10(4), 427-441. http://dx.doi.org/10.1177/1368430207081533

Turner, R.N., Hewstone, M., \& Voci, A. (2007). Reducing explicit and implicit prejudice via direct and extended contact: The mediating role of self-disclosure and intergroup anxiety. Journal of Personality and Social Psychology, 93(3), 369-388. http://dx.doi.org/10.1037/0022-3514.93.3.369

Turner, R. N., Hewstone, M., Voci, A., \& Vonofakou, C. (2008). A test of the extended intergroup contact hypothesis: The mediating role of intergroup anciety, perceived ingroup and outgroup norms, and inclusion of the outgroup in the self. Journal of Personality and Social Psychology, 95(4), 843-860. http://dx.doi.org/10.1037/a0011434

Van Houtte, M. (2004). Why boys achieve less at school than girls: the difference between boys' and girls' academic culture. Educational Studies, 30(2), 159-173. http://dx.doi.org/10.1080/0305569032000159804

Voci, A. \& Hewstone, M. (2003). Intergroup contact and prejudice towards immigrants in Italy: The meditational role of anxiety and the moderational role of group salience. Group Processes and Intergroup Relations, 6(1), 37-54. http://dx.doi.org/10.1177/1368430203006001011

Whitaker, P., Barratt, P., Helen, J., Potter, M., \& Thomas, G. (1998). Children with autism and peer group support: "Using circles of friends". British Journal of Special Education, 25, 60-64.

Wolpe, J. (1958). Psychotherapy by reciprpocal inhibtion. Stanford, CA: Stanford University Press.

Wright, S. C., Aron, A., McLaughlin-Volpe, T., \& Ropp, S. A. (1997). The extended contact effect: Knowledge of cross-group friendships and prejudice. Journal of Personality and Social Psychology, 73(1), 73-90. http://dx.doi.org/10.1037/0022-3514.73.1.73 